\title{
Tritium Distribution Modeling in a Light Water New Production Reactor
}

\author{
J. W. Jaeckle
}

May 1989

Prepared for the U.S. Department of Energy under Contract DE-AC06-76RLO 1830

Pacific Northwest Laboratory Operated for the U.S. Department of Energy by Battelle Memorial Institute 


\section{DISCLAIMER}

This report was prepared as an account of work sponsored by an agency of the United States Government. Neither the United States Ciovernment nor any agency thereof, nor Battelle Memorial Institute, nor any or their employees, makes any warranty, expressed or implied, or assumes any legal liability or responsibility for the accuracy, completeness, or usefulness of any information, apparatus, product, or process disclosed, or represents that its use would not infringe privately owned rights. Reference herein to any specific commercial product, process, or service by trade name, trademark, manufacturer, or otherwise does not necessarily constitute or imply its endorsement, recommendation, or favoring by the United States Government or any agency thereof, or Battelle Memorial Institute. The views and opinions of authors expressed herein do not necessarily state or reflect those of the United States Government or any agency thereof.

\section{PACIFIC NORTHWEST LABORATORY operated by \\ BATTELLE MEMORIAL INSTITUTE for the \\ UNITED STATES DEPARTMENT OF ENERGY under Contract DE-AC06-76RLO 1830}

\begin{tabular}{|c|c|}
\hline \multicolumn{2}{|c|}{ Printed in the United States of America } \\
\hline & \\
\hline \multicolumn{2}{|c|}{ National Technical Information Service } \\
\hline \multicolumn{2}{|c|}{ United States Department of Commerce } \\
\hline \multicolumn{2}{|c|}{5285 Port Royal Road } \\
\hline \multicolumn{2}{|c|}{ Springfield, Virginia 22161} \\
\hline \multicolumn{2}{|c|}{ NTIS Price Codes } \\
\hline \multicolumn{2}{|c|}{ Microfiche A01 } \\
\hline \multicolumn{2}{|c|}{ Printed Copy } \\
\hline & Price \\
\hline Pages & Codes \\
\hline $001-025$ & $\mathrm{~A} 02$ \\
\hline $026-050$ & A03 3 \\
\hline $051-075$ & A04 \\
\hline $076-100$ & A05 \\
\hline $101-125$ & $\mathrm{~A} 06$ \\
\hline $126 \cdot 150$ & $\mathrm{~A} 07$ \\
\hline $151 \cdot 175$ & $\mathrm{~A} 0 \mathrm{~A}$ \\
\hline $176-200$ & A09 \\
\hline 201-225 & A 10 \\
\hline $226-250$ & A11 \\
\hline $251 \cdot 275$ & A12 \\
\hline $276-300$ & A13 \\
\hline
\end{tabular}


TRITIUM DISTRIBUTION MODELING IN A LIGHT WATER NEW PRODUCTION REACTOR

J. H. Jaeckle

May 1989

Prepared for the U.S. Department of Energy under Contract DE-ACO6-76RLO 1830

Pacific Northwest Laboratory

Richland, Hashington 99352 



\section{EXECUTIVE SUMMARY}

The tritium distribution and tritium release pathways in a new light water production reactor were examined. A computer model was developed to track the tritium as it makes its way through the various plant systems and ends up either as a release to the atmosphere, the cooling tower blowdown or to the solid waste system. The model was designed to predict the integrated yearly tritium releases and provide estimated airborne tritium concentrations in various locations within the plant. WNP-1 was used as a representative model for a Light Water New Production Reactor (LWNPR).

The Tritium Distribution Model solves for the time dependent tritium concentration in a system of nodes. These nodes are connected to one another via a set of internodal flow paths and to various sources and sinks. For example, plant systems such as the primary system are the nodes, piping and leaks are the internodal flow paths, make-up water is a source, and release to the atmosphere is a sink. The expected water mass of each node; the flow rates between nodes, sources, and sinks; and tritium source rates are provided as input. The code will solve for the time dependant tritium concentration in each node and the amount of tritium "released" to the sinks.

Preliminary calculations have been performed using WNP-1 plant specific information obtained primarily from the WNP-1 FSAR. Further work is currently in progress to refine the model and provide a more realistic set of input values which will better represent an operating LWNPR. 


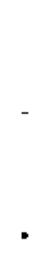




\section{CONTENTS}

EXECUTIVE SUMMARY ...................

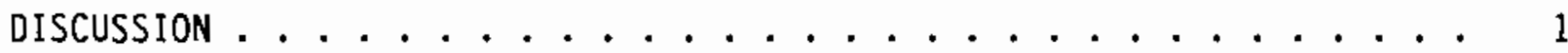

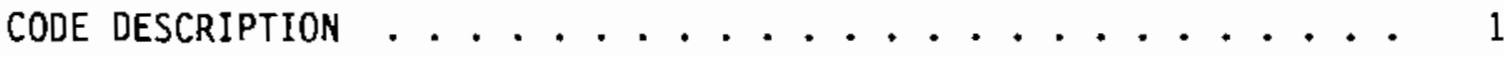

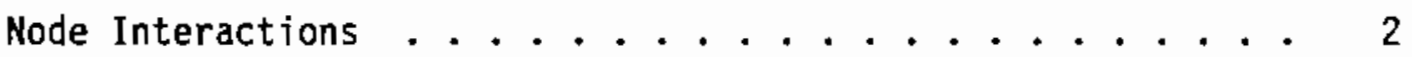

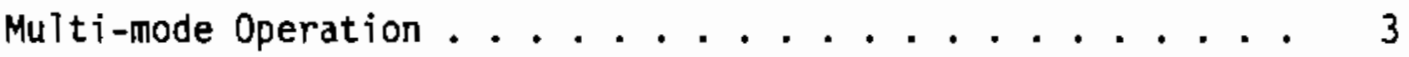

Computer Code Solution Methodology ......... 3

LWNPR MODEL DESCRIPTIONS ................ . . 4

Building Vapor/Liquid Model ............... 5

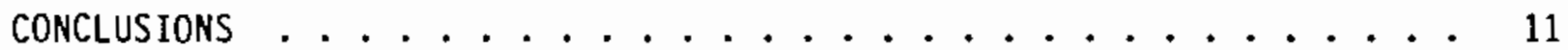

REFERENCES ............................ 12 


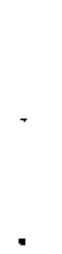




\section{DISCUSSION}

\section{CODE DESCRIPTION}

The Tritium Distribution Model (TDM) code is designed to solve for the time dependant concentration of tritium in a system of nodes and calculate the tritium released via the various pathways from the system of nodes on a yearly basis. The code is not set up to provide an accurate day-by-day account of the tritium concentration and tritium releases from the system of nodes.

The code is set up to solve for the time dependant tritium concentrations of a given number of nodes (i.e., plant systems). The concentration has the units of mass of tritium per mass of water. For this analysis the mass units chosen were $1 b_{m}$. Each node is assumed to maintain a constant mass of water. This assumption is made possible because of the year time frame. The mass inventory of the modeled systems will fluctuate over the year, however, these fluctuations are expected to be about some mean value. Because of this, over an extended time frame, using this mean value as the constant mass is possible. A good example of this situation is the water inventory in building sumps. These sumps have a high level switch which activates the pump when the high level is reached. The pump continues operation until the water level in the sumps reaches the lower level limit. Throughout the year the sump will be filled to a level between these two limits.

The introduction of variable mass nodes into the model was considered. Variable mass nodes would have enabled the model to provide accurate tritium distributions on a shorter time scale. Variable mass nodes were not incorporated in to the code because obtaining sufficiently accurate data was unlikely. Much of the data provided for the model is in the form of expected yearly values or some average value based on past industry experience. These average values are acceptable when one is mainly interested in the integrated annual tritium releases. The day-to-day variations of these values is highly dependant on the specific plant and how it is operated. The possible increase in accuracy from variable mass nodes was not needed for the objectives of this study.

Each node is modeled to have a uniform tritium concentration. For systems such as the primary this assumption is quite true. For system composed of 
several tanks such as the liquid rad waste system (LRW), this assumption is made possible because of the long time frame. Also, in such a system, leaks will occur throughout the system. These leaks will have somewhat different tritium concentrations, but taken on the whole the leaks can be modeled as one integrated leak at the uniform system concentration.

\section{Node Interactions}

As previously described, the code uses a set of constant mass nodes in solving for the time dependant tritium concentration in each node. Each node can interact with the other nodes by means of an internodal flow of water. This flow may be deliberate as in the case of primary system shim bleed to the boron recovery system (BRS) or in the form of system leakage such as leakage from the liquid rad waste system draining to the general services building sumps. These flows may be from any one node to any other node as specified by input. The flows are expressed in the units of mass of water per unit time. In this analysis, the flow rates were in $1 b_{m} / h r$.

Each node is able to have an external source of water. This source of water is expected to have some fixed concentration of tritium $\left(1 b_{m}\right.$ tritium/ $1 b_{m}$ water) which is specified by the input. This source can be tritiated or clean water. This is the mechanism by which clean leaks into a system or addition of makeup water are handled.

Each node may also be connected to any of a number of "sinks". Typically these would be the atmosphere, blowdown, and the solid waste system (SWS). These sinks are treated as accumulators of tritium, a tritium concentration is never calculated for them. A "counter" is placed on them which keeps track of the amount of tritium entering each sink from each system.

Tritium is also removed from each system by means of radioactive decay (12.33yr half life). Whenever tritium is present in any system it is subject to decay, as the tritium passes into a sink, it is counted. This accumulated sink count is not subject to decay. Decay of tritium from a system changes only the amount of tritium in the system, not the water inventory.

Tritium may be added to a system in the form of a "mass source"s such as a target rod. A mass source only adds tritium to a system ( $1 b_{m}$ tritium/hr), not any water mass. 
In order to maintain a constant node mass, the sum of the water flows out of the node (to other nodes or sinks) must equal the sum of the water flows into the node (from other nodes or a source). The user is responsible to see that the input reflects this exactly. Small deviations from this will result in the failure of the model due to the accumulating effects of mass loss or gain over years of operation.

\section{Multi-mode Operation}

The code is constructed so that the user can define sets input parameters (flows, etc.) applicable over a length of time (specified by input). One of these sets reflects conditions during a specific mode of plant operation, such as power operation or refueling. The code then "cycles" through these various input sets in the order specified. A new set of parameters may be used for each "cycle". The user may also transfer water inventory between the nodes at the start of each cycle, but this transfer process is restricted to only two different transfer modes which are specified upon input for each cycle.

The transfer process permits the mixing of nodes to form "mixed nodes" at the mixture concentration. When a node is mixed, part or all of its water inventory may be transferred to another node. Upon going back to the original transfer mode, the "mixed node" is reestablished in its original form by mean of transferring water back to the nodes where it originated. For example, in going from "mode 1" to "mode 2", node A transfers $1000 \mathrm{lb}$ of water to node B and $2000 \mathrm{lb}$ of water to node $C$ and retains $3000 \mathrm{lb}$; then upon going from "mode 2" to "mode 1", node B will transfer back $10001 \mathrm{~b}$ to node $A$ and node $C$ will transfer back $2000 \mathrm{lb}$ to node $A$. The user specifies how and which of the nodes are to be mixed.

Computer Code Solution Methodology

The model developed requires the solution of a system of first order differential equations, given a set of initial conditions. Each equation solves for the time dependant concentration of one of the nodes. Given that the mass of the $i$ th node is constant and equal to $M_{i}$, the differential equation for that node's concentration is given by the simple balance equation 
$\begin{aligned} & \text { Rate of change } \\ & \text { of node } \\ & \text { concentration }\end{aligned}=\frac{1}{M_{i}} \times\{$ (rate of tritium in) - (rate of tritium out) $\}$.

The rates of tritium addition to a node are: the sum of the internodal flows into the node times the respective concentration of the node from which they originated; the external source flow times its concentration; and any tritiun mass source.

The rates of tritium removal from a node are: the sum of the internodal flows from the node times the node's concentration; the sum of flows from the node to the sinks times the node's concentration; and radioactive decay in the node.

A fourth order Runge-Kutta method was used to solve the system of equations. A number of sample cases were run where the exact analytical solution could be found to validate the method. The sample cases consisted of systems of one and two nodes having various interconnections, sources, and sinks. By varying the time step size the model produced the solution to the accuracy desired.

For example, in the actual LWNPR modeling, a time step size of five hours was used. To insure this time step size provided sufficient accuracy, runs were made using $I$ and 10 hour time steps. At the end of 274 days, all the corresponding system concentrations were in agreement for the three time step sizes. Nodes of small mass and high flow require very small time step sizes and should be avoided. They will reach equilibrium quickly and so may usually be bypassed.

\section{LWNPR MODEL DESCRIPTIONS}

In trying to provide a more realistic picture of the yearly operation, the year was broken down into a number of distinct operational modes. In preliminary LWNPR modeling, three operational modes were modeled. These were power operation, refueling (with vessel open), and cold shutdown. Each of the modes has its own set of input parameters specific to the mode's operating conditions. The use of these three operating modes per year provides a more accurate yearly prediction of tritium distribution and releases. 
For the power operation mode the reactor was assumed to operate for 274 full power days. During the power run the reactor is expected to have an availability factor of $90 \%$. This sets the length of the power run to 304 days. During this time the reactor is expected to remain hot and pressurized.

The refueling operation when the vessel is open is expected to require 16 days. During this mode the inventory of the refueling water tank is added to the refueling canal. This water mixes with the primary water to form a "refueling primary" of much greater mass.

The cold shutdown mode is implemented next for the remainder of the year (45 days). During this time the primary is expected to be cold and depressurized, and extensive maintenance is expected to be performed.

In modeling the tritium distribution in a LWNPR a total of nine systems were modeled. Figure 1 shows these systems and a representative set of flow interconnections. Table 1 contains a sample set of input parameters needed to describe the system in Figure 1 for the various modes of operation.

\section{Building Vapor/Liquid Model}

When a plant system experiences a leak, the leak is exposed to the building atmosphere and is subject to evaporation/condensation. The leak may originate entirely as liquid or as a two phase mixture. For example, leaks from the hot primary system appear originally with about $40 \%$ steam quality with the remainder as saturated liquid at $100^{\circ} \mathrm{C}$. Part of the leak will make its way to a floor drain and end up in the building sumps. The sumps are covered and all penetrations are sealed. For this reason, the water in the sumps is relatively well isolated from the building vapor space. The remainder of the leak will eventually be released to the atmosphere via the building ventilation system.

An accurate evaporation/condensation and building transport model is beyond the scope of this work. United Engineers \& Constructors provided data as to the estimated final liquid/vapor split after evaporation of some of the leaks. This information is based on FSAR data and past experience.

The four locations within the plant where one must look at vapor/liquid interactions are the containment, general services building (GSB), turbine 
To Atmosphere

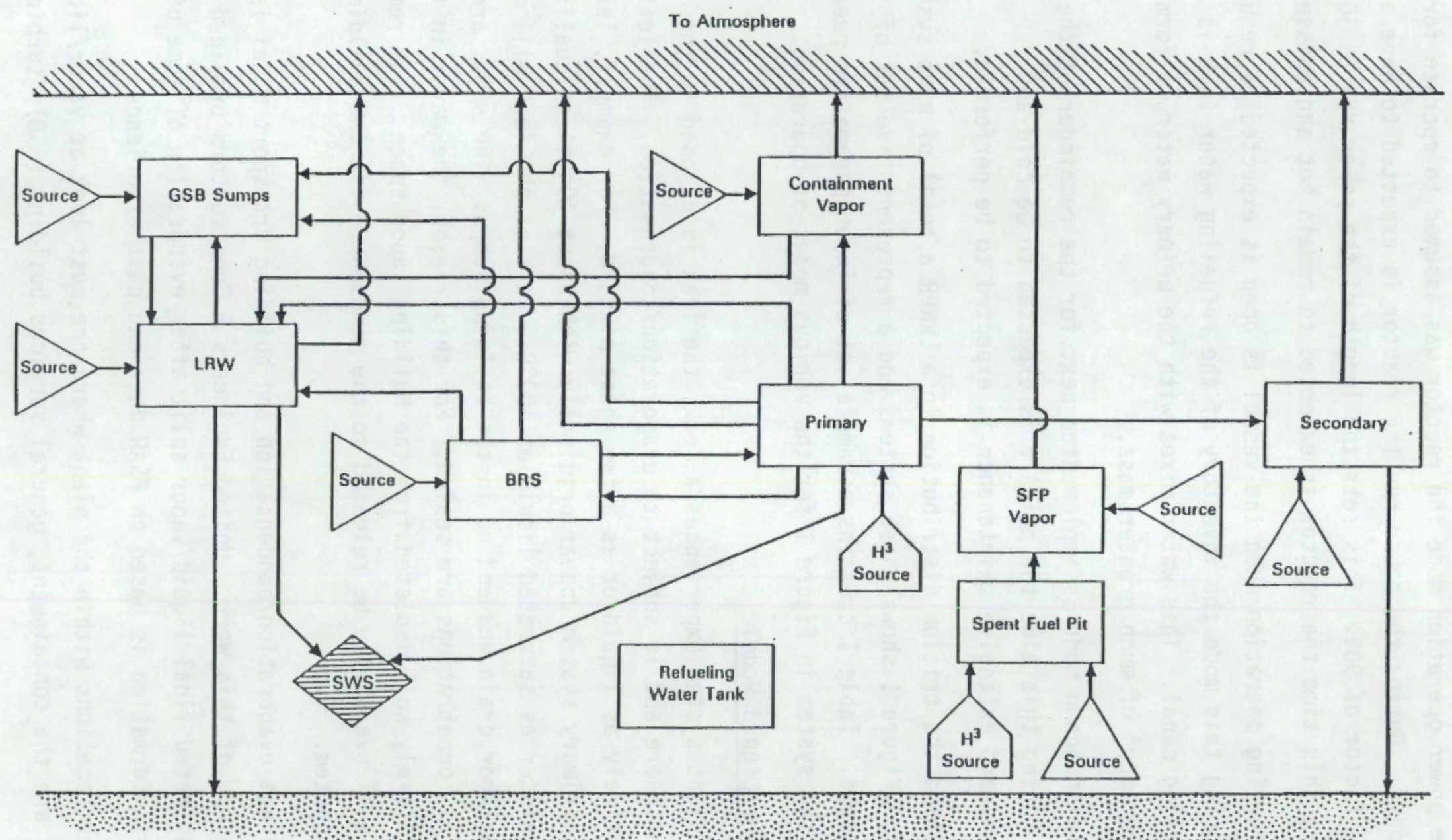

Blowdown

FIGURE 1. System Layout 
TABLE 1. Input Parameters

\section{CASE}

Input Parameter

By System

Power/Refueling/Shutdown

PRIMARY

Mass (1b)

Tritium Source

$(\mathrm{lb} / \mathrm{hr})$

Flow (lb/hr) to:

- Cont. Vapor

- Secondary

- BRS

- LRW

- GSB Sumps

- GSB Atmosphere

- SWS

CONTAINMENT VAPOR

Mass (Ib)

Clean Water Source

$(1 \mathrm{~b} / \mathrm{hr})$

Flow (1b/hr) to:

- LRW

- Atmosphere

SECONDARY

Mass (lb)

Clean Water Source $(\mathrm{lb} / \mathrm{hr})$

Flow (lb/hr) to:

- Atmosphere

- Blowdown

BORON RECOVERY SYSTEM

Mass (1b)

Clean Water Source

$(1 \mathrm{~b} / \mathrm{hr})$

Flow (1b/hr) to:

- Primary

- LRW

- GSB Sumps

- GSB Atmosphere 
TABLE 1. Input Parameters (cont.)

CASE

Input Parameter

By System

Power/Refueling/Shutdown

LIQUID RAD WASTE SYSTEM

Mass (1b)

Clean Water Source

$(\mathrm{lb} / \mathrm{hr})$

Flow (lb/hr) to:

- GSB Sumps

- GSB Atmosphere

- Blowdown

- SWS

GSB SUMPS

Mass (lb)

Clean Water Source

(1b/hr)

Flow $(1 \mathrm{~b} / \mathrm{hr})$ to:

- LRW

SPENT FUEL POOL

Mass (1b)

Tritium Source

(lb/hr)

Clean Water Source

(1b/hr)

Flow (1b/hr) to:

- S.F. Pool Vapor

S.F. POOL VAPOR

Mass (1b)

Clean Water Source

( $\mathrm{lb} / \mathrm{hr}$ )

Flow (1b/hr) to:

- Atmosphere

REFUELING WATER TANK

Mass (Ib) 
building, and the spent fuel handling area. The spent fuel handling area is in the general services building, but is isolated from the rest of the building.

The vapor spaces of the GSB and turbine building are not treated as systems in the LWNPR model. The ventilation system in these buildings provides for rapid air exchanges. The vapor portion of leaks in these buildings is modeled as going directly to the atmosphere. The atmospheric tritium concentration in these buildings is assumed to be equal to the sum of the vapor leak rates times the leak's concentration divided by the building's ventilation rate. This assumption assumes homogeneous mixing of the vapor leaks throughout the building and gives a building average airborne tritium concentration. In reality, the airborne tritium concentrations will be greater than the average near the source of the leak.

The vapor portion of the containment building and the spent fuel handling area are modeled as systems. The mass of water in these systems is obtained by using appropriate values of the expected temperature and relative humidity in the building along with the building's free volume. The TDM solution is performed on this water mass. The flow of water from the building's atmosphere is found using the building temperature, relative humidity, and the ventilation rate. The ventilation system will also introduce a source of water into the building by means of the humidity of the incoming air. The yearly average water content of the outside air was found in the WNP-1 FSAR (WPPSS, 1986).

The spent fuel pool and the refueling canal both provide a free surface for evaporation and condensation. In the case of the spent fuel handling area the evaporation rate is taken as the rate of water removed from the atmosphere via the vents minus the rate of incoming water with the ventilation. This assumes transport of water is only out of the pool at its surface. The FSAR provides a specific value for the evaporation rate from the refueling water.

The sumps inside containment and the turbine building are not modeled as systems. The contents of the containment sumps are pumped to the liquid rad waste system and the contents of the turbine building sumps are routed to the cooling tower blowdown. Because of the relatively small size of the containment sumps and the large throughput of water in the turbine bujlding sumps, and the single system flow input to each, the model simply bypasses 
these sumps and directs the flows to their final destination. The GSB sumps are modeled as systems since they have a significant combined mass and receive flow from a number of plant systems. They receive "dirty" water from various systems (primary, BRS, LRW), as well as a significant amount of "clean" water mainly from leaks of component cooling water in the GSB. 


\section{CONCLUSIONS}

The Tritium Distribution Model at its present level of development may be used to provide a first order estimate of the annual releases of tritium from a LWNPR. The TDM will track the tritium concentration throughout a set of plant systems during a given operating cycle, provided that the mass of water in each system and the inflows and outflows from each system can be assumed to be constant over the operating cycle. The TDM lacks a precise evaporation/condensation model and relies instead upon empirical input data that reflects the correct liquid/vapor split of leaks to building atmospheres.

Future work will focus on obtaining more precise plant data which is more representative of expected plant conditions during operations and on obtaining a better understanding of tritium transport inside of building atmospheres. 


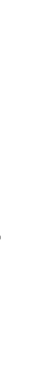




\section{REFERENCES}

Washington Public Power Supply System (WPPSS). 1986. WNP-1 FSAR. Richland, Washington. 


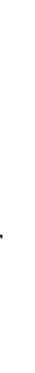




\section{DISTRIBUTION}

No. of

Copies

OFFSITE

10 DOE/Office of Scientific and Technical Information

N. Amaria

United Engineers \& Constructors

P.0. Box 460

Richland, WA 99352

R. Blond

SAIC

U.S. Department of Energy NP -40

1000 Independence Ave., S.W. Washington, DC 20585

G. A. Dinneen

Idaho National Engineering Laboratory

EG\&G Idaho

P.0. Box 1625

Idaho Falls, ID 83415-2514

H. P. 0lson

Savannah River Laboratory

Building 773-41A

Aiken, SC 29808
No. of

Copies

ONSITE

DOE Richland Operations office

D. M. Smith

4 Westinghouse Hanford Company

A. J. Duckett

H. W. Heacock

R. P. Omberg

R. C. Ross

10 Pacific Northwest Laboratory

L. R. Dodd

S. W. Heaberl in

J. W. Jaeckle

A. W. Prichard

Publishing Coordination

Technical Report Files (5) 
